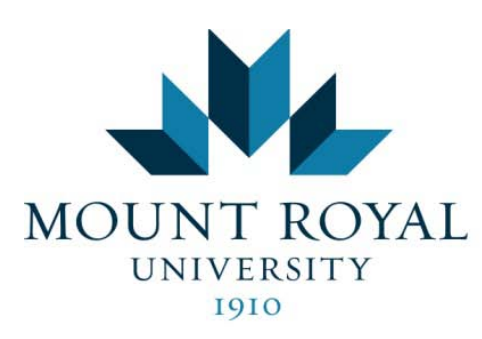

Mount Royal Undergraduate Education Review
Department of Education and Schooling

Volume 1(2)

Fall 2014

\title{
Digital technology for elementary English language learning (ELL) students
}

\section{Danielle Hendricks, Mount Royal University}

$\underline{\text { Link to Digital Story }}$

\begin{abstract}
English language learners (ELL) are students who are learning English not as their first, but as second or even third language. A lot of the time these students do not speak English at home because they use their first language as the primary home language. These students may only get the opportunity to learn to speak English in school. In early elementary, kindergarten through Grade three, the primary focus is to develop language and literacy skills which will prepare the students for further educational learning. The old saying is that; first you learn to read and then you read to learn. In this study, I questioned how technology can be used to engage the early elementary ELL students to develop language and literacy skills. I conducted an anonymous survey and an email interview to gather my data. I found my results were inconclusive for determining which technologies would benefit the ELL elementary teacher in helping to develop language and literacy skills. There are many valuable technologies available, however, further research will be necessary to draw any distinct conclusions
\end{abstract}




\section{Introduction}

When I was in elementary school I struggled with learning to read and write. I loved listening to people read to me, however, I still struggled with the independent literacy skills. As I advanced through my education the struggles I had in literacy began to create a noticeable difference in the educational abilities between myself and my peers. Falling behind in my literacy development lead to all around poor grades, anxiety, depression and social isolation. The harder school became, the lower my confidence, efficacy and esteem fell. As a future early elementary school teacher I recognize the importance of developing language and literacy skills within all students at this critical point in their education.

In my Mount Royal University, Bachelor of Education degree program I have had the opportunity to work with students who are also struggling with literacy development. In particular I have noticed students who are learning English as a second language have a particularly difficult curve in literacy. As a Teaching English as a Second Language minor student, I became very interested in how to help early elementary ELL students develop language and literacy skills in a meaningful, engaging and fun way. I wanted to find out what drives students intrinsically to develop the literacy skills they will need to be confident and fluent in their educational practices.

In this new era of technology, I have noticed there is an opportunity to offer students new methods and techniques to acquire language and literacy through the use of technology. Technology can afford students all types of universal learning methods which could ultimately make learning English more engaging and meaningful. I wanted to find out what these technologies were, how they were being implemented and if teachers found them useful for helping to develop language and literacy skills in ELL students. 
I also wanted to explore how students can most effectively acquire English at school without homework requirements. Many students’ parents are also ELL, therefore, the primary language spoken at home would not be English. I believe that first language acquisition should continue to be a priority for children and families within their homes and communities. Canada is proudly multicultural and we need to ensure people have the opportunity to maintain their culture. Language is one of the primary factors in cultural identity, I believe English language acquisition should take place within the school not the home.

\section{Background}

Through the papers I have examined it would appear there are many technologies that can be used to support ELL students in their language and literacy development. Language and literacy development is a strong focus in schools today, "Currently in education systems globally, there is a focus on Early Years curricula and literacy and numeracy standards” (McDonald \& Howell, 2012, p. 641). Through the papers I have included, I want to discover how teachers can best support their students' language and literacy development through the use of these technologies.

Daniel, Dong Shin, Harrison and Aoki (2014) discusses the effects of technologies, used for literacy, with ELL students.

We examine current technologies' contributions to the curriculum. We discuss supporting English language learners' (ELLs) school based literacy development through integration of technologies for mainstream classrooms and for schools with populations of ELLs like Lola. As well, we highlight available technologies for language and literacy instruction. (p. 35) 
Daniel et al. (2014) highlights how Web 2.0, Voki and other web based technologies can impact the students. The article focuses on the impact of language domains including listening, speaking, reading, and writing skills. The discussion of these technologies made me want to know which technologies are teachers using in their practice when helping ELL students develop language and literacy skills.

Roessingh (2011) examines young English language learners in the context of culture and identity as they develop early literacy and English language skills.

The goal of this paper is to advance a framework for early language and literacy development that takes into account the multiple and complex learning needs of these children, who are usually referred to as English language learners (ELLs) in current research literature. (p. 124)

Beginning to examine how teachers are able to develop ELL students' language and literacy through the development of identity has become a very important focus for my research. The students build meaningful context through a dual-language book project that is initiated with culturally based object they brought from home. Roessingh (2011) expands on the importance of creating the context for development.

The Family Treasures Project used the 'third space' in an attempt to create a context for vocabulary development in the L1 and L2 that was interesting, culturally sensitive, and responsive; that would encourage parental involvement; and that was grounded in something concrete (an object), something which had personal meaning and would inspire narrative construction. (p. 140)

This article has inspired me to develop a portion of my research around dual language books and how teachers use this technology to develop language and literacy in ELL students. 
McDonald and Howell (2012) look at the implementation of the LEGO Robotics Program WeDo@ in an early elementary school classroom. The student participants in this study are primarily second language learners. McDonald and Howell (2012) explain their findings "The impact of the pilot project was very positive in a number of areas: (1) student engagement, (2) the development of literacy and numeracy skills and (3) the development of interpersonal skills” (p. 646). These results are significant because my research is focusing of literacy skills development. McDonald and Howell (2012) go on to explain the significance of their discoveries, "There appears to be an extraordinary opportunity to use creative digital technologies to bridge the gap between Indigenous, NESB and non-Indigenous literacy and numeracy standards” (p. 649). The research is trying to prove the beneficial impact technology can have on bridging the gap between English as a first language and English as a second language students.

Rodriguez, Filler and Higgins (2012) examine the use of technology based reading support for students who are learning English as a second language.’Technology may play an important role in the education of ELL learners as it has the potential to provide more opportunities for them to learn language” (Rodriguez et al., 2012, p. 254). The participants are divided into two groups, one with only English support and the other with first language support. The students who had technology support from their first language did remarkably better in reading comprehension, "The students who received Spanish language support via the computer had significantly higher scores in the area of reading comprehension” (Rodriguez et al., 2012, p. 253).

Young and Wang (2014) explore the integration of games with speech recognition technology to promote English language learning in students whose first language is not English, 
“The aim of this study is to make a new attempt to explore the potential of integrating game strategies with automatic speech recognition technologies to provide learners with individual opportunities for English pronuniation learning” (p.239). The study finds that students are more engaged in learning through the automatic feedback and motivating challenges they receive from the game. Young and Wang (2014) elaborate “The game-like and relaxed learning scenarios of GeCALL may be a trigger that fosters learners, both at the advanced and low-achievement levels, to join together practicing speaking in a pleasurable learning environment” (p. 249).

Through the review of these papers and studies I have found significant developments in exploring how teachers can engage early elementary students who are learning English as a second language, to develop early literacy through the use of technology.

\section{Research Context and Methods of Investigation}

Prior to beginning my research data collection I completed the online Government of Canada Ethics Certificate. This training provided me with the information I needed to know about conducting ethical research.

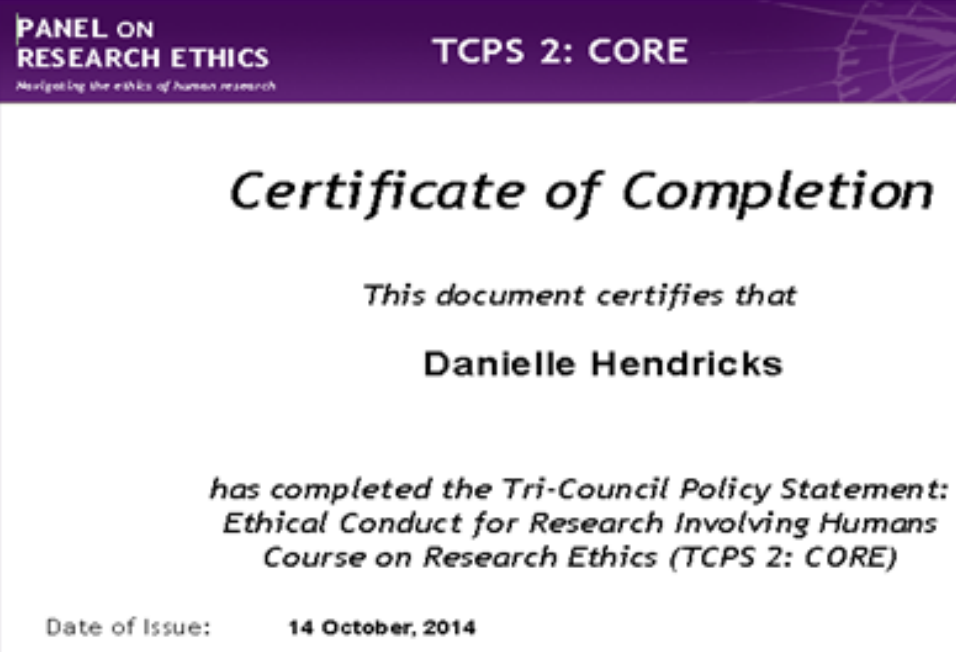

Figure 1. Canadian Ethics Course Certificate 
To begin my collection, I gathered my data using an online survey which I created using Google. Most of the participants of the survey are other undergraduate education students and teachers or faculty with relevant experience. Participation in the survey was anonymous, I did not request any names, emails or personal information that could identify an individual. The survey was emailed to students, teachers and faculty, it was also posted on Twitter and Facebook. Seventeen anonymous individuals participated in my online survey. After closing the survey I analyzed the data using pie charts from the summary responses provided by Google. I also made word clouds using Tagxedo to analyze the written responses I gathered from the survey.
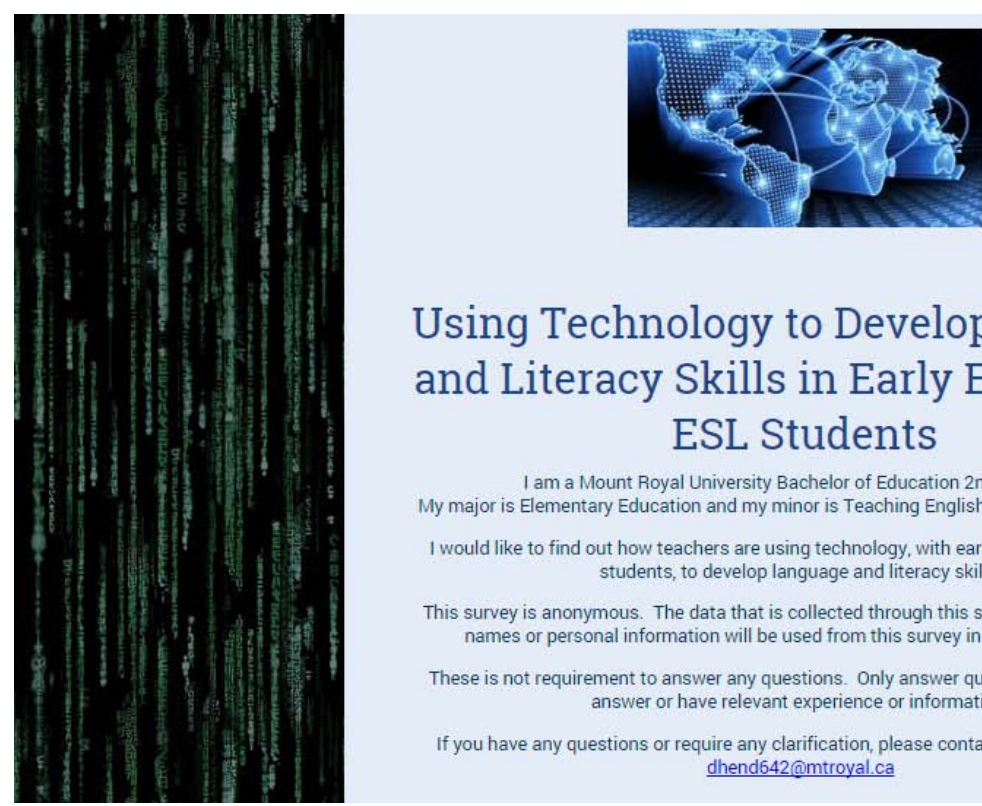

\section{Using Technology to Develop Language} and Literacy Skills in Early Elementary ESL Students

I am a Mount Royal University Bachelor of Education 2nd student. My major is Elementary Education and my minor is Teaching English as a Second Language. I would like to find out how teachers are using technology, with early elementary $(k-3)$ ESL students, to develop language and literacy skills.

This survey is anonymous. The data that is collected through this survey is anonymous, no names or personal information will be used from this survey in any related report.

These is not requirement to answer any questions. Only answer questions you are able to answer or have relevant experience or information.

If you have any questions or require any clarification, please contact Danielle Hendricks; dhend642@mtroyal.ca

Figure 2. Online Survey

After gathering my survey data, I conducted an email interview with Hetti Roessingh, the author of the paper Family treasures: A dual-language book project for negotiating language, literacy, culture, and identity, which I had used to develop my background (2011). I was introduced to Hetti Roessingh by my instructor through email correspondence. Hetti Roessingh provided me with a more current research paper and specific examples regarding how preservice 
teachers can use technology to develop language and literacy skills in elementary students. I analyzed Hetti Roessingh’s responses by reading her email several times to extract key ideas and concepts while looking for key missing information.

\section{Findings}

The collection and analysis of the data I have gathered has been organized according to the questions I have posed in the survey and in my email correspondence with Hetti Roessingh. I have displayed the data visually in charts and word clouds to help interpret the results. The following figures demonstrate the anonymous results that were gathered from my online survey.

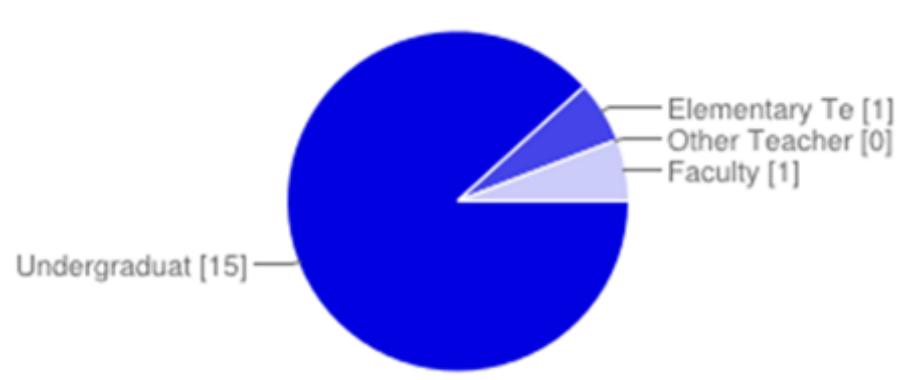

$\begin{array}{lrr}\text { Who are you? } & & \\ \text { Undergraduate Student } & \mathbf{1 5} & 88 \% \\ \text { Elementary Teacher } & \mathbf{1} & 6 \% \\ \text { Other Teacher } & \mathbf{0} & 0 \% \\ \text { Faculty } & \mathbf{1} & 6 \%\end{array}$

Figure 3. Who are You?

The majority of survey participants were undergraduate students. This should be noted as important because many of these students may not have had the opportunity to work with ELL students in developing language and literacy skills. I did indicate in the survey criteria that participants should have had experience working with early elementary ELL students, however, there is no way of confirming whether or not this request was followed. In future surveys, I will include a question confirming the requested participant criteria. 
Have you used any technologies, with early elementary ESL students, to develop language and literacy skills?

Yes $\quad 5 \quad 29 \%$

No $12 \quad 71 \%$

Figure 4. Using Technology

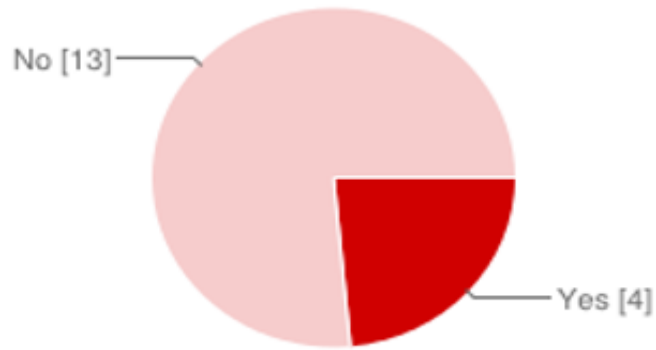

Figure 5. eBooks

Have you used duel language eBooks to support language and literacy development in early elementary ESL students?

Yes $1 \quad 6 \%$

No $16 \quad 94 \%$

Figure 6. eBooks and ESL

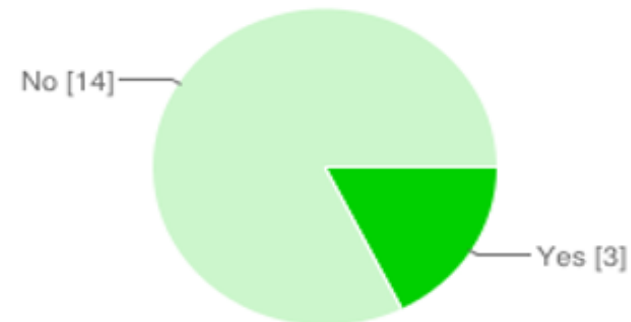

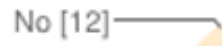

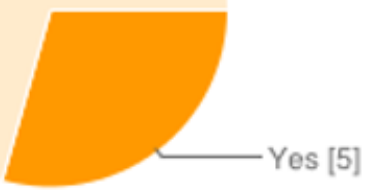

Have you used eBooks to engage early elementary ESL students in literacy and language development?

Yes $4 \quad 24 \%$

No $13 \quad 76 \%$
Have you used a translator tool to support, early elementary, ESL students with language and literacy development?

Yes $\quad 3 \quad 18 \%$

No $\quad 14 \quad 82 \%$

Figure 7. Translator Tool

Through these charts I was able to assess what type of individuals are participating in my 
survey and how they have been able to use technology with ELL students to develop language and literacy skills. I was also able to see the percentage of people who are actually using these technologies. My findings indicated that the participants have not had very much experience working with technology to develop the language and literacy skills of elementary ELL students.

I used word clouds to analyze the written responses that was provided in my online survey. I found the word clouds do an excellent job of extracting the more dominant information and ideas within the text.

\section{What translator software have you used?}

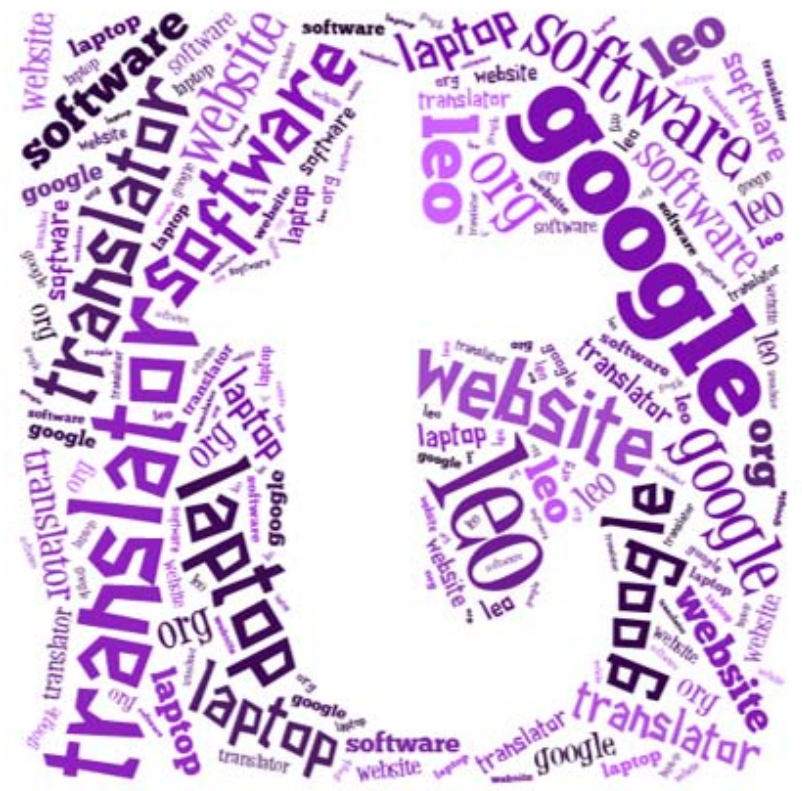

Figure 8. Translator Software

The translator software that was identified as being used by the participants most often included Google Translate and leo.org. I would be interested in speaking with more teachers who have used translator software to determine if there are other useful translator tools available to ELL teachers. 


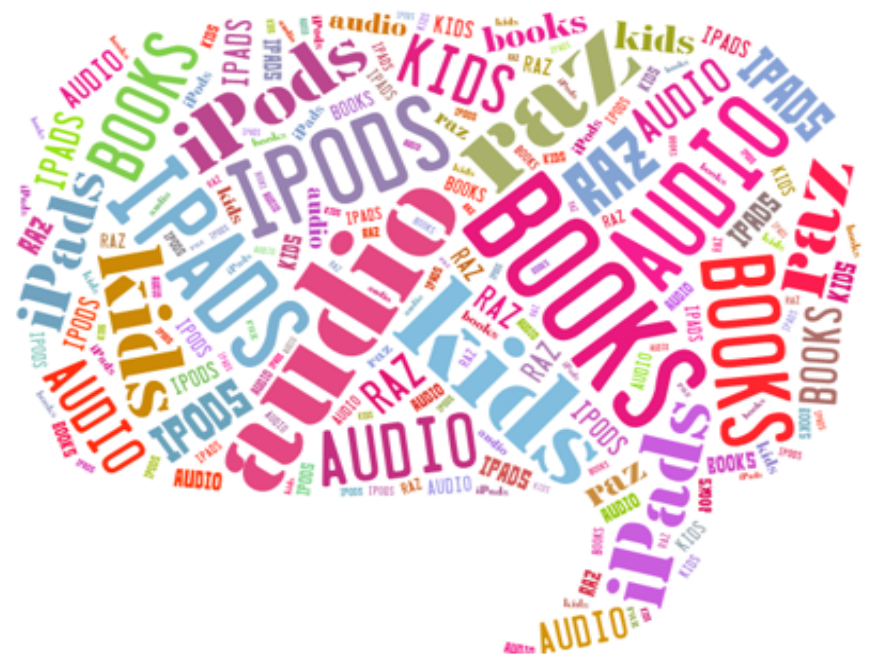

Are there any OTHER types of technology have you used, with early elementary ESL students, to support language and literacy development?

Figure 9. Other Technologies

The dominant findings for this question, about other technologies, were audio books, Raz Kids and YouTube have been used support ELL students’ language and literacy development. Hetti Roessingh stated in her email to me "YouTube clips, nice websites, etc. for them to listen, read and learn!” (2014). I believe there are more technology tools available, however, they have not shown up in this data.

What type of technologies do you think works best for supporting language and literacy development in early elementary ESL students?

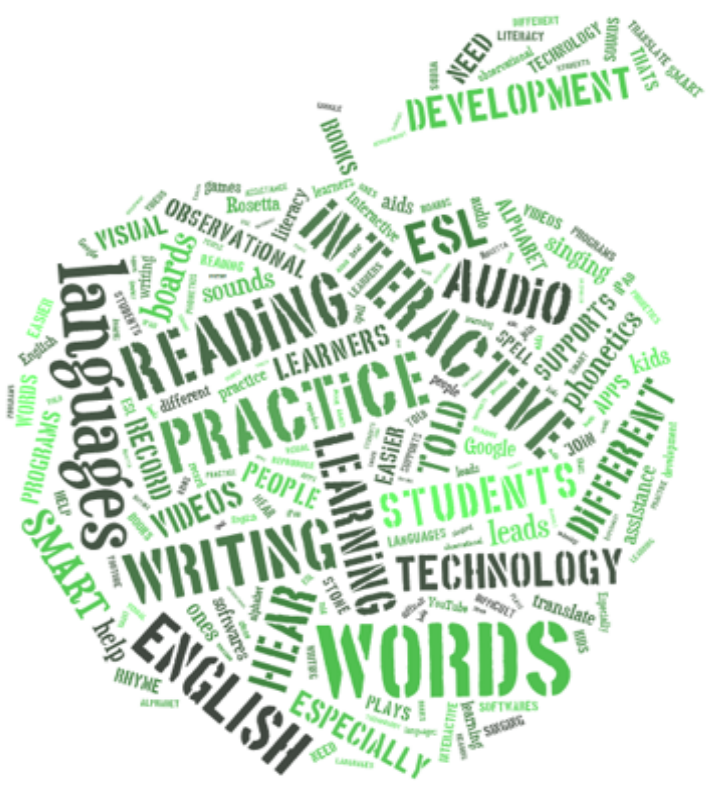

Figure 10. Support from Technologies 


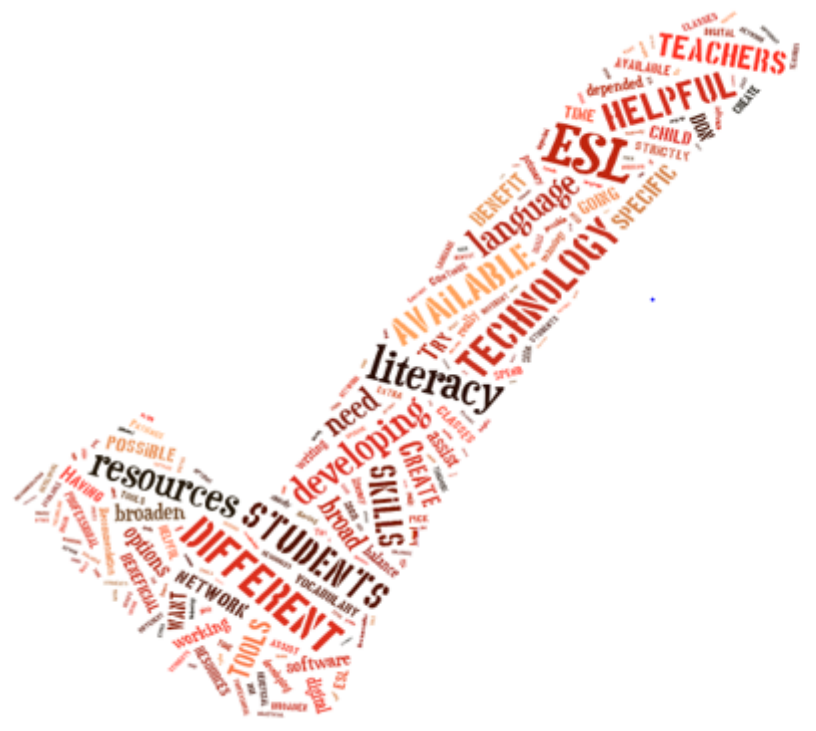

Do you have any recommendations for my future teaching career as an early elementary school teacher who will be working with ESL students to develop language and literacy skills?

Figure 11. Recommendations

\section{Conclusions and Recommendations}

I was initially somewhat disappointed with the results I collected from my data, I found the data to be insufficient due to low survey participation. Through my survey, email communication and the additional paper provided to me by Hetti Roessingh, I was able to determine that I did not gathered sufficient information on the topic to make any significant determinations about using technology to help ELL students develop language and literacy skills. Furthermore, Hetti Roessingh (2014) states, “The research literature related to its potential with young ELLs who must develop sufficient academic language and literacy proficiency to compete with their native speaking peers in the mainstream class setting remains under-developed” ( p. 7). This statement confirms my belief about the lack of available information regarding this topic. However, I do believe there is an opportunity and need for further research in this area. It was through my analysis of the data I have determined that my finding are more indicative of there being a greater need for further research and study on this subject.

It had also come to my attention through this research that a more important question I should have been asking was: how can teachers cultivate the interests and motivations of the 
students through technology to enhance the development of language and literacy skills? In the additional research presented by Hetti Roessingh (2014), she discussed how technology can be used to develop these skills, "Locating sites with listening opportunities for enriched input is especially important for ELLs, given that few of them have exposure to sophisticated English vocabulary in their evening hours with their families” (p. 7).

I believe technology can afford ELL students opportunities which would be unavailable to them without the influence of technology. Hetti Roessingh (2014) states, "From interesting websites, to accessing the daily newspaper, to YouTube clips, children have learned that there is a world of information available at their fingertips” (p. 16). Students now have the advantage of unlimited resources due to the influence of technology and teachers can use this resource to build motivation to learn through interests the students bring to the classroom. In my future undergraduate studies at MRU I plan to continue to study how I can cultivate the interests and motivations of all of my students, especially my ELL students, through the use of technology to enhance the development of their language and literacy skills.

\section{References}

Daniel, M. C., Dong Shin, S., Harrison, C., \& Aoki, E. (2014). Examining paths to digital literacies for English language learners. Illinois, USA. Illinois Reading Council Journal, 42(4), 35-42.

McDonald, S., \& Howell, J. (2012). Watching, creating and achieving: Creative technologies as a conduit for learning in the early years. British Journal of Educational Technology, 43(4), 641-651. doi:10.1111/j.1467-8535.2011.01231.x 
Rodriguez, C., Filler, J., \& Higgins, K. (2012). Using primary language support via computer to improve reading comprehension skills of first-grade English language learners. Computers in the Schools, 29(3), 253-267. doi:10.1080/07380569.2012.702718

Roessingh, H. (2011). Family treasures: A dual-language book project for negotiating language, literacy, culture, and identity. Canadian Modern Language Review, 67(1), 123148. doi:10.3138/cmlr.67.1.123

Roessingh, H. (2014). Teachers' roles in designing meaningful tasks for mediating language learning through the use of ICT: A reflection on authentic learning for young ELLs. Canadian Journal of Learning and Technology, Special Issue on ICT mediated language tasks, 40 (1), 1 - 24. http://www.cjlt.ca/index.php/cjlt/article/viewFile/782/387

Young, S. S., \& Wang, Y. (2014). The game embedded CALL system to facilitate English vocabulary acquisition and pronunciation. Journal of Educational Technology \& Society, 17(3), 239-239, 251. Retrived from

http://search.proquest.com/docview/1556988024?accountid=1343 